\title{
ARTICLE
}

Epidemiology

\section{Female reproductive factors and the risk of lung cancer in postmenopausal women: a nationwide cohort study}

\author{
Keun Hye Jeon ${ }^{1}$, Dong Wook Shin $\mathbb{1}^{1,2}$, Kyungdo $\mathrm{Han}^{3}$, Dahye $\mathrm{Kim}^{3}$, Jung Eun Yoo ${ }^{1,4}$, Su-Min Jeong ${ }^{1,5}$ and Jong ho Cho ${ }^{6}$
}

BACKGROUND: Reproductive factors and hormone use in postmenopausal women have been hypothesised to affect the risk of developing lung cancer, but the epidemiological evidence is inconsistent.

METHODS: Using the Korean National Health Insurance System database, we identified 4,775,398 postmenopausal women older than 40 years who had undergone both cardiovascular health- and cancer screening between 1 January 2009 and 31 December 2014. Information about reproductive factors was obtained from a self-administered questionnaire. The risk of lung cancer was estimated using Cox proportional hazard regression models.

RESULTS: During a median follow-up of 4.4 years, 16,556 women $(15,223$ non-smokers) were diagnosed with lung cancer. The risk of lung cancer was not significantly influenced by early menarche age (adjusted hazard ratio [aHR] 1.03 for menarche $\geq 18$ vs. $\leq 14$; 95\% confidence interval [Cl], 0.98-1.09) or late age at menopause (aHR 1.02 for menopause $\geq 55$ vs. $<40 ; 95 \% \mathrm{Cl}, 0.91-1.14$ ). Furthermore, the number of children, duration of breastfeeding and use of hormone replacement therapy were not associated with the risk of lung cancer.

CONCLUSIONS: No statistically significant association was found between reproductive factors and the risk of lung cancer in postmenopausal Korean women.

British Journal of Cancer (2020) 122:1417-1424; https://doi.org/10.1038/s41416-020-0789-7

\section{BACKGROUND}

Lung cancer is the leading cause of cancer deaths worldwide, and the third most common cancer in women, after breast- and colorectal cancer. ${ }^{1}$ In most countries, including Korea, the incidence of lung cancer in women is increasing, whereas in men, it has decreased or stabilised., ${ }^{2,3}$

Lung cancer in women has several characteristics that differ from lung cancer in men. Although smoking is the most important risk factor, a significant portion of lung cancer in women occurs in non-smokers. ${ }^{4}$ Global statistics estimate that $20 \%$ of lung cancer in Western populations develops in non-smokers. ${ }^{1}$ In Korea, $38 \%$ of female non-small-cell lung cancer patients reported themselves to be non-smokers. ${ }^{5}$ Female lung cancer patients have a higher proportion of adenocarcinoma histology, ${ }^{6}$ and a higher frequency of mutations in the epidermal growth factor receptor (EGFR) ${ }^{7}$ than male lung cancer patients. Such sex-related differences suggest that hormonal factors might influence the development of lung cancer.

Hormonal involvement in lung carcinogenesis was first suggested by experimental studies that identified oestrogen and progesterone receptors in human lung cancers. ${ }^{8}$ Steroid hormonerelated receptors, including oestrogen receptors, progesterone receptors and human epidermal growth factor receptor 2 , are frequently expressed in tumour lung tissue, ${ }^{8-10}$ and have been linked to survival in lung cancer patients. ${ }^{11,12}$ Oestrogen receptor a nuclear expression correlates significantly with adenocarcinoma histology, female sex and a history of never smoking. ${ }^{9}$ In addition, a recent study revealed a sex-related difference in oestrogen receptor $\beta$ nuclear expression. ${ }^{8}$

As a result, it has been hypothesised that reproductive factors and hormone use could affect women's risk of developing lung cancer. However, the epidemiological evidence is inconsistent and does not fully support that hypothesis. For example, with respect to late age at menopause, studies have variously shown an increase, $^{13,14}$ a decrease ${ }^{15,16}$ or no significant change ${ }^{17-19}$ in lung cancer risk; early age at menarche has been shown to increase ${ }^{15}$ or have no significant effect ${ }^{16,18-20}$ on risk; a small number of pregnancies has been shown to increase, ${ }^{19,21,22}$ decrease ${ }^{20}$ and have no significant effect ${ }^{15,18}$ on risk; late age at first birth might decrease $\mathrm{s}^{20}$ or have no significant effect ${ }^{15,16,18,22}$ on risk. Studies on the use of hormones have also produced heterogeneous results: the use of oral contraceptives has been shown to increase ${ }^{16}$ or have no significant effect ${ }^{18-20,22-26}$ on risk, and the use of hormone replacement therapy (HRT) might increase, ${ }^{27,28}$ decrease ${ }^{17,29,30}$ or have no appreciable influence ${ }^{15,18,19,25,31,32}$ on risk.

\footnotetext{
${ }^{1}$ Department of Family Medicine and Supportive Care Centre, Samsung Medical Centre, Sungkyunkwan University School of Medicine, Seoul, Korea; ${ }^{2}$ Department of Digital Health, Samsung Advanced Institute for Health Science and Technology (SAIHST), Sungkyunkwan University, Seoul, Korea; ${ }^{3}$ Department of Medical Statistics, The Catholic University of Korea, Seoul, Korea; ${ }^{4}$ Department of Economics and Centre for Economic and Social Research, University of Southern California, Los Angeles, and RAND Corporation, Santa Monica, CA, USA; ${ }^{5}$ Department of Nutrition Epidemiology, TH Chan School of Public Health, Harvard University, Boston, MA, USA and ${ }^{6}$ Department of Thoracic Surgery, Samsung Medical Centre, Sungkyunkwan University School of Medicine, Seoul, Korea

Correspondence: Dong Wook Shin (dwshin.md@gmail.com) or Kyungdo Han (hkd917@naver.com)
}

Received: 10 July 2019 Revised: 18 February 2020 Accepted: 27 February 2020

Published online: 17 March 2020 
Previous cohort studies have been limited by small sample size (cohort studies published between 2001 and 2015 included 87-3512 lung cancer cases ${ }^{15-22,27,29-34}$ ), and case-control designs prone to recall bias. Moreover, the potential association between hormone exposure and lung cancer has not been comprehensively elucidated because several studies focused exclusively on exogenous hormone use. ${ }^{25,27-32,35}$

Furthermore, even though lung cancer in East Asia shows unique patterns in epidemiology ${ }^{7}$ and treatment response, ${ }^{36}$ few studies have been conducted there. East Asian females with lung cancer generally show lower smoking prevalence $(9.9 \%$ in Korea, $5.2 \%$ in China ${ }^{7}$ and $17-25.6 \%$ in Japan ${ }^{37}$ ) than is common in Western countries. Several case-control studies have been carried out in China and Singapore, but only a few cohort studies have been conducted in Asian countries-1 in Japan, ${ }^{18} 2$ in China ${ }^{22,33}$ and 2 in Singapore. ${ }^{19,21}$

In this study, we investigate the association between reproductive factors and the risk of lung cancer among postmenopausal women in a nationwide population cohort in Korea.

\section{METHODS}

Data source and study setting

The Korean National Health Insurance Service (NHIS) is the single insurer that provides universal insurance for $\sim 97 \%$ of the South Korean population. The remaining $3 \%$ of the population (in the lowest-income bracket) is covered by the Medical Aid program financed by the government, but it is also administered by the NHIS.

The NHIS provides national health check-up programmes, including a general health examination focused on cardiovascular risk factors, for all citizens aged 40 and above, and all employees regardless of age. ${ }^{38}$ It records the results of those general health examinations and questionnaires on lifestyle behaviour. In addition, the NHIS provides the National Cancer Screening Program (NCSP), ${ }^{39}$ which screens all individuals for stomach, liver, colorectal, breast and cervical cancers, as indicated by age. ${ }^{39}$ During our study period, Korean women were eligible to participate in biennial screening for breast cancer beginning at age 40 and cervical cancer beginning at age $30 .^{39}$

The NHIS has qualification data on all its enrolees (age, sex, income level and mortality), diagnosis codes from the International Classification of Disease 10th revision (ICD-10), medical treatment information (medical services provided for medical expense claims) and prescription information. ${ }^{40,41}$ To manage enrolee qualification, the NHIS updates its mortality data through frequent links with mortality data from the Korean National Statistical Office. The NHIS database is widely used in epidemiological studies investigating disease incidence, ${ }^{42-44}$ and the details of the database profiles are described elsewhere. ${ }^{38,40,45,46}$ This study was approved by the Institutional Review Board of Samsung Medical Centre (IRB File No. SMC 2018-05-020).

Study population and data collection

From the NHIS database, we collected data for women older than 40 who had undergone both a cardiovascular health screening and an NCSP (breast/cervical cancer) screening between 1 January 2009 and 31 December 2014. Among 4,775,398 postmenopausal women who qualified, those who had previously been diagnosed with cancer $(n=167,910)$, participants diagnosed with any cancer within 1 year after the date of examination $(n=55,937)$, individuals who had previously undergone a hysterectomy $(n=$ $17,667)$, participants who died within 1 year after examination $(n=4565)$ and those missing data in a key variable $(n=4116)$ were excluded. We excluded those who had previously undergone a hysterectomy because the questionnaire provided no information about the timing of the hysterectomy, and whether a bilateral oophorectomy had been performed concurrently. After those exclusions, a total of 4,525,203 individuals were included in our analyses (Fig. 1).

Information about health-related behaviours, and the menstrual and reproductive histories of participants, was obtained using a self-administered questionnaire. Participants came to the medical centre on the day of the screening examination, and filled out the questionnaire prior to the exam. According to the NCSP guidelines, women were asked about their age at menarche and age at menopause as continuous variables. For analysis purposes, we categorised age at menarche as $\leq 14$ years, 15-16 years, 17 years and $\geq 18$ years, and age at menopause as $<40$ years, $40-44$ years, $45-49$ years, $50-54$ years and $\geq 55$ years. The reproductive period was calculated as the interval between the age at menarche and age at menopause. Information on parity number, total lifetime breastfeeding history, HRT history and the use of oral contraceptives was collected categorically: parity number $(0,1$ or $\geq 2$ children), total lifetime breastfeeding history (never, $<6$ months, 6-12 months and $\geq 12$ total months), duration of HRT (never, $<2$ years, $2-5$ years, $\geq 5$ years and unknown) and duration of oral contraceptive use (never, $<1$ year, $\geq 1$ year and unknown).

Participants' history of smoking was classified as never smoked, former and $<10$ pack-years smoker, former and $\geq 10$ pack-years smoker, current and $<10$ pack-years smoker and current and $\geq 10$ pack-years smoker. Drinking was divided into three levels: none, mild ( $<30 \mathrm{~g}$ of alcohol/day) and heavy ( $\geq 30 \mathrm{~g} /$ day). Regular exercise was defined as moderate physical activity for more than $30 \mathrm{~min}$, and more than 5 days per week during the past week. Body mass index (BMI) was calculated using weight $(\mathrm{kg})$ divided by height in metres squared $\left(\mathrm{m}^{2}\right)$, and classified as low $\left(<18.8 \mathrm{~kg} / \mathrm{m}^{2}\right)$, normal to overweight $\left(18.5-24.9 \mathrm{~kg} / \mathrm{m}^{2}\right)$ and obese $\left(\geq 25 \mathrm{~kg} / \mathrm{m}^{2}\right)$. Hypertension, diabetes and dyslipidaemia were defined using physicians' diagnoses or the use of medication,

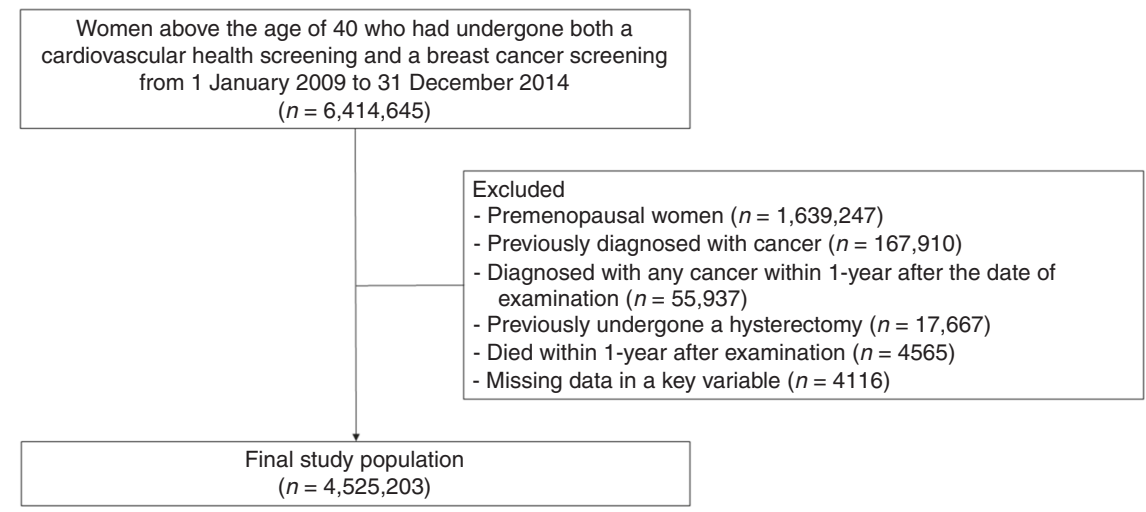

Fig. 1 Flow chart of the cohort study design. 
based on self-reporting. Household income was categorised into quartiles based on insurance premium levels (in Korea, insurance premiums are determined by income level), with those covered by Medical Aid (poorest 3\%) being merged into the lowest-income quartile.

\section{Study outcomes and follow-up}

The primary endpoint of this study was newly diagnosed lung cancer, defined as new claims for inpatient or outpatient care with the ICD-10 diagnosis code of C34 (malignant neoplasm of lung and bronchus), and registration in the special co-payment reduction programme for critical illnesses. The NHIS special copayment reduction programme for cancer and some other intractable diseases relieves the large financial burden of patients with serious and rare diseases. For example, cancer patients pay only $5 \%$ of the total medical bill incurred for cancer diagnostic tests or treatment. As enrolment in this programme requires a medical certificate from a physician, the cancer diagnosis variable in our study is considered sufficiently reliable, and has been used in other studies. ${ }^{42,44}$ The cohort was followed from 1 year after the health check-up date to the date of incident lung cancer, death or the end of the study period (31 December 2016), whichever came first.

\section{Statistical analysis}

Continuous variables are presented as the mean \pm standard deviation, and categorical variables are presented as the number and percentage. The incidence rates of lung cancer were calculated by dividing the number of incident cases by the total follow-up period. Hazard ratios (HRs) and 95\% confidence interval $(\mathrm{Cl})$ values for lung cancer were analysed using Cox proportional hazard models for various reproductive factors. A multivariableadjusted proportional hazard model was applied: (1) model 1 was age-adjusted; (2) model 2 was adjusted for age at menarche and menopause, parity, duration of breastfeeding, duration of HRT, duration of oral contraceptive use, alcohol consumption, smoking, regular exercise, income, BMI, hypertension, diabetes mellitus, dyslipidaemia and cancer; (3) model 3 was adjusted for reproductive period instead of age at menarche and menopause separately, as in model 2. Statistical analyses were performed using SAS version 9.4 (SAS Institute Inc., Cary, NC, USA), and a $P$ value $<0.05$ was considered statistically significant.

\section{RESULTS}

Baseline characteristics of study participants

During a mean follow-up of 4.4 years $(19,910,975$ person-years), 16,556 women $(15,223$ non-smokers) were diagnosed with lung cancer, for an incidence rate of 83.15 cases per 100,000 personyears. Table 1 provides the baseline information and characteristics of the study population. The mean age of the study participants was 61.2 years. Among all participants, only $3.1 \%$ were current smokers, $91.9 \%$ had breastfed and $14.6 \%$ had received HRT.

Compared with the women not diagnosed with lung cancer, lung cancer cases had a higher mean age at study entry (65.9 vs. 61.3 years), a higher proportion of current and past smokers (6.5 and 1.6 vs. 3.1 and 1.1\%), a tendency to exercise less (35.5 vs. $40.2 \%$ ), more hypertension (51.4 vs. $42.3 \%$ ) and more diabetes (16.7 vs. $13.8 \%)$. With respect to reproductive factors, only the duration of breastfeeding differed; the proportion of women breastfeeding for $\geq 1$ year in lung cancer patients was $73.8 \%$, which was higher than that among women not diagnosed with lung cancer $(66.1 \%)$. The mean ages of menarche and menopause for lung cancer patients and the non-case group were 16.6 vs. 16.3 and 50.0 vs. 50.2 years, respectively, and the mean reproductive period was 33.4 vs. 33.9 years. Supplementary Table 1 provides a baseline characteristic analysis according to smoking status.
Associations between reproductive factors and the risk of lung cancer

None of the menstrual or reproductive variables analysed showed a statistically significant association with lung cancer (Table 2). In multivariate-adjusted model 2, the HRs for lung cancer were 1.03 (95\% Cl, 0.98-1.09) for those whose age at menarche was $\geq 18$ years compared with those aged $\leq 14$ years, $1.02(95 \% \mathrm{Cl}$, $0.91-1.14$ ) for those whose age at menopause was $\geq 55$ years compared with those $<40$ years old, 0.95 (95\% Cl, 0.84-1.06) for the group having $\geq 2$ parity compared with those with nulliparity, 0.95 (95\% Cl, 0.88-1.02) for the group breastfeeding for $\geq 1$ year compared with those with no breastfeeding history, $1.04(95 \% \mathrm{Cl}$, 0.95-1.15) for the group on HRT for $\geq 5$ years compared with the never-HRT group and $1.06(95 \% \mathrm{Cl}, 0.99-1.13)$ for the patients who had used oral contraception for $\geq 1$ year compared with neverusers. Furthermore, when model 3 was adjusted for reproductive period instead of age at menarche and menopause as in model 2, similar trends were observed. The reproductive period was calculated as the interval between the age at menarche and the age at menopause, indicating a strong correlation among those variables. Therefore, we analysed them separately. Moreover, a sensitivity analysis restricted to non-smokers showed no statistically significant association between reproductive factors and the risk of lung cancer (Supplementary Table 2).

Other factors associated with lung cancer

Compared with never-smokers, current smokers were at a significantly increased risk for lung cancer (aHR 1.98; $95 \% \mathrm{Cl}$, $1.80-2.17$ for $<10$ pack years and aHR $3.40 ; 95 \% \mathrm{Cl}, 3.12-3.69$ for $\geq 10$ pack years). The risk of lung cancer in women who were former smokers also remained elevated compared with neversmokers (aHR 1.27; 95\% Cl, 1.08-1.49 for $<10$ pack years and aHR 2.59; $95 \% \mathrm{Cl}, 2.14-3.14$ for $\geq 10$ pack years). Hypertension was associated with a slightly elevated risk of lung cancer (aHR 1.05; $95 \% \mathrm{Cl}, 1.01-1.08)$. Alcohol consumption, physical activity, BMI, diabetes mellitus, dyslipidaemia and income level were not statistically significant in the multivariable analyses.

\section{DISCUSSION}

In the largest cohort study to date, we found that a wide range of reproductive history measures made no consistent contributions to lung cancer risk. The strengths of our study include an unprecedentedly large representative sample size and outcome incidence (more than 4.5 million women with 16,556 incident lung cancer cases), a comprehensive evaluation of the reproductive variables of interest and minimal follow-up losses (1.3\%).

None of the menstrual variables analysed in our study showed a statistically significant association with lung cancer. Decades ago, a case-control study reported that a later age at menopause was associated with an increased lung cancer risk, ${ }^{13,14}$ whereas more recent studies found that a later age at menopause was associated with a reduced risk of lung cancer. ${ }^{15,47}$ With respect to menarche, Brinton et al. ${ }^{15}$ reported that early menarche was associated with an increased risk of adenocarcinoma, and a few other studies reported an increased risk for lung cancer with a later age at menarche, but the risk estimates were not statistically significant. ${ }^{19,22}$ Most other studies reported null associations. ${ }^{16,20,22,23,26,48-54}$ Weiss et al. reported that a longer reproductive period was associated with a decrease in the risk of lung cancer (HR 0.60 for 36 vs. $<31$ years; 95\% Cl, 0.39-0.93), ${ }^{22}$ but other studies reported null associations. ${ }^{18,21,33}$ Overall, previous studies showed that menstrual variables were not consistently associated with lung cancer risk, and our results support that finding.

Concerning parity, Kabat et al. reported an increased risk with increasing parity in Canada, ${ }^{20}$ but most other cohort studies reported an inverse association ${ }^{19,21-23,55}$ or null effect. ${ }^{15,17,18,26,48,50,51,53,56,57}$ 
Table 1. Selected baseline characteristics of the study population.

\begin{tabular}{|c|c|c|c|}
\hline Variable & $\begin{array}{l}\text { Total } \\
(N=4,525,203)\end{array}$ & $\begin{array}{l}\text { Women not } \\
\text { diagnosed with } \\
\text { lung cancer } \\
(N=4,508,647)\end{array}$ & $\begin{array}{l}\text { Women } \\
\text { diagnosed with } \\
\text { lung cancer } \\
(N=16,556)\end{array}$ \\
\hline Mean age, y (SD) & $61.2(8.7)$ & $61.3(8.7)$ & $65.9(8.7)$ \\
\hline \multicolumn{4}{|c|}{ Age at menarche, no. (\%) } \\
\hline Mean (SD) & $16.3(1.9)$ & $16.3(1.9)$ & $16.6(1.9)$ \\
\hline$\leq 14$ y & $712,179(15.7)$ & $710,254(15.8)$ & $1925(11.6)$ \\
\hline $15-16 y$ & $1,806,866(39.9)$ & $1,800,693(39.9)$ & $6173(37.3)$ \\
\hline $17 \mathrm{y}$ & $854,123(18.9)$ & $850,758(18.9)$ & $3365(20.3)$ \\
\hline$\geq 18$ y & $1,152,035(25.5)$ & $1,146,942(25.4)$ & $5093(30.8)$ \\
\hline \multicolumn{4}{|c|}{ Age at menopause, no. (\%) } \\
\hline Mean (SD) & $50.2(4.0)$ & $50.2(4.0)$ & $50.0(4.4)$ \\
\hline$<40$ y & $73,474(1.6)$ & $73,120(1.6)$ & $354(2.1)$ \\
\hline $40-44$ y & $237,584(5.3)$ & $236,500(5.3)$ & $1084(6.6)$ \\
\hline $45-49 y$ & $1,172,184(26.0)$ & $1,167,918(25.9)$ & $4266(25.8)$ \\
\hline $50-54 y$ & $2,510,733(55.5)$ & $2,501,988(55.5)$ & $8745(52.8)$ \\
\hline$\geq 55$ y & $531,228(11.7)$ & $529,121(11.7)$ & $2107(12.7)$ \\
\hline \multicolumn{4}{|c|}{ Reproductive period, no. (\%) } \\
\hline Mean (SD) & $33.9(4.4)$ & $33.9(4.4)$ & $33.4(4.7)$ \\
\hline$<30 y$ & $562,807(12.4)$ & $560,192(12.4)$ & $2615(15.8)$ \\
\hline $30-34$ y & $1,768,024(39.1)$ & $1,761,249(39.1)$ & $6775(40.9)$ \\
\hline $35-39 y$ & $1,844,270(40.8)$ & $1,838,391(40.8)$ & $5879(35.5)$ \\
\hline$\geq 40$ & $350,102(7.7)$ & $348,815(7.7)$ & $1287(7.8)$ \\
\hline \multicolumn{4}{|l|}{ Parity, no. (\%) } \\
\hline Nulliparous & $99,224(2.2)$ & $98,847(2.2)$ & $377(2.3)$ \\
\hline 1 child & $347,461(7.7)$ & $346,491(7.7)$ & $970(5.9)$ \\
\hline$\geq 2$ children & $4,078,518(90.1)$ & $4,063,309(90.1)$ & $15,209(91.9)$ \\
\hline \multicolumn{4}{|c|}{ Duration of breastfeeding, no. (\%) } \\
\hline Never & $366,238(8.1)$ & $365,176(8.1)$ & $1062(6.4)$ \\
\hline$<0.5$ y & $362,575(8.0)$ & $361,738(8.0)$ & $837(5.1)$ \\
\hline 0.5 to $<1$ y & $804,665(17.8)$ & $802,226(17.8)$ & $2439(14.7)$ \\
\hline$\geq 1$ y & $2,991,725(66.1)$ & $2,979,507(66.1)$ & $12,218(73.8)$ \\
\hline \multicolumn{4}{|c|}{ Hormone therapy, no. (\%) } \\
\hline Never used & $3,696,024(81.7)$ & $3,682,200(81.7)$ & $13,824(83.5)$ \\
\hline$<2$ y & $392,482(8.7)$ & $391,279(8.7)$ & $1203(7.3)$ \\
\hline 2 to $<5 y$ & $150,713(3.3)$ & $150,263(3.3)$ & $450(2.7)$ \\
\hline$\geq 5 \mathrm{y}$ & $119,890(2.7)$ & $119,457(2.7)$ & $433(2.6)$ \\
\hline Missing & $166,094(3.7)$ & $165,448(3.7)$ & $646(3.9)$ \\
\hline \multicolumn{4}{|c|}{ Oral contraceptive use, no. (\%) } \\
\hline Never used & $3,646,833(80.6)$ & $3,633,551(80.6)$ & $13,282(80.2)$ \\
\hline$<1 \mathrm{y}$ & $397,111(8.8)$ & $395,766(8.8)$ & $1345(8.1)$ \\
\hline$\geq 1 \mathrm{y}$ & $261,279(5.8)$ & $260,236(5.8)$ & $1043(6.3)$ \\
\hline Missing & $219,980(4.9)$ & $219,094(4.9)$ & $886(5.4)$ \\
\hline \multicolumn{4}{|c|}{ Smoking history, no. (\%) } \\
\hline Never smoked & $4,335,259(95.8)$ & $4,320,036(95.8)$ & $15,223(92.0)$ \\
\hline Former smoker & $51,171(1.1)$ & $50,912(1.1)$ & $259(1.6)$ \\
\hline Current smoker & $138,773(3.1)$ & $137,699(3.1)$ & $1074(6.5)$ \\
\hline \multicolumn{4}{|c|}{ Pack years of smoking, no. (\%) } \\
\hline Never smoker & $4,335,259(95.8)$ & $4,320,036(95.8)$ & $15,223(92.0)$ \\
\hline $\begin{array}{l}\text { Former smoker } \\
\&<10\end{array}$ & $40,881(0.9)$ & $40,729(0.9)$ & $152(0.9)$ \\
\hline $\begin{array}{l}\text { Former smoker } \\
\& \geq 10\end{array}$ & $10,290(0.2)$ & $10,183(0.2)$ & $107(0.7)$ \\
\hline $\begin{array}{l}\text { Current smoker } \\
\&<10\end{array}$ & $91,170(2.0)$ & $90,685(2.0)$ & $485(2.9)$ \\
\hline $\begin{array}{l}\text { Current smoker } \\
\& \geq 10\end{array}$ & $47,603(1.1)$ & $47,014(1.0)$ & $589(3.6)$ \\
\hline \multicolumn{4}{|l|}{ Drinker } \\
\hline None & $3,908,753(86.4)$ & $3,894,093(86.4)$ & $14,660(88.6)$ \\
\hline Mild & $594,527(13.1)$ & $592,711(13.2)$ & $1816(11.0)$ \\
\hline Heavy & $21,923(0.5)$ & $21,843(0.48)$ & $80(0.5)$ \\
\hline $\begin{array}{l}\text { Regular physical } \\
\text { activity }\end{array}$ & $1,819,153(40.2)$ & $1,813,280(40.2)$ & $5873(35.5)$ \\
\hline
\end{tabular}

\begin{tabular}{|c|c|c|c|}
\hline Variable & $\begin{array}{l}\text { Total } \\
(N=4,525,203)\end{array}$ & $\begin{array}{l}\text { Women not } \\
\text { diagnosed with } \\
\text { lung cancer } \\
(N=4,508,647)\end{array}$ & $\begin{array}{l}\text { Women } \\
\text { diagnosed with } \\
\text { lung cancer } \\
(N=16,556)\end{array}$ \\
\hline \multicolumn{4}{|c|}{ Body mass index, no. (\%) } \\
\hline$<18.5 \mathrm{~kg} / \mathrm{m}^{2}$ & $102,774(2.3)$ & $102,319(2.3)$ & $455(2.8)$ \\
\hline 18.5 to $<23 \mathrm{~kg} / \mathrm{m}^{2}$ & $1,608,543(35.6)$ & $1,602,747(35.6)$ & $5796(35.0)$ \\
\hline 23 to $<25 \mathrm{~kg} / \mathrm{m}^{2}$ & $1,182,847(26.1)$ & $1,178,649(26.1)$ & $4198(25.4)$ \\
\hline 25 to $<30 \mathrm{~kg} / \mathrm{m}^{2}$ & $1,428,031$ (31.6) & $1,422,676(31.6)$ & $5355(32.3)$ \\
\hline$\geq 30 \mathrm{~kg} / \mathrm{m}^{2}$ & $203,008(4.5)$ & $202,256(4.5)$ & $752(4.5)$ \\
\hline \multicolumn{4}{|l|}{ Co-morbid condition } \\
\hline $\begin{array}{l}\text { Hypertension, } \\
\text { no. (\%) }\end{array}$ & $1,915,482(42.3)$ & $1,906,972(42.3)$ & $8510(51.4)$ \\
\hline DM, no. (\%) & $622,758(13.8)$ & $619,999(13.8)$ & $2759(16.7)$ \\
\hline $\begin{array}{l}\text { Dyslipidaemia, } \\
\text { no. (\%) }\end{array}$ & $1,657,900(36.6)$ & $1,651,724(36.6)$ & $6176(37.3)$ \\
\hline SBP & $125.3 \pm 16$ & $125.3 \pm 16$ & $127.4 \pm 16.2$ \\
\hline DBP & $76.7 \pm 10.0$ & $76.7 \pm 10.0$ & $77.3 \pm 10.1$ \\
\hline Glucose & $100.4 \pm 23.9$ & $100.4 \pm 23.9$ & $101.6 \pm 24.7$ \\
\hline Cholesterol & $207.0 \pm 38.8$ & $207.0 \pm 38.8$ & $205.0 \pm 39.1$ \\
\hline \multicolumn{4}{|l|}{ Income } \\
\hline Q1 (lowest) & $1,277,758(28.2)$ & $1,273,270(28.2)$ & $4488(27.1)$ \\
\hline Q2 & $1,007,569(22.3)$ & $1,004,198(22.3)$ & $3371(20.4)$ \\
\hline Q3 & $1,056,997(23.4)$ & $1,053,003(23.4)$ & $3994(24.1)$ \\
\hline Q4 (highest) & $1,182,879(26.1)$ & $1,178,176(26.1)$ & $4703(28.4)$ \\
\hline
\end{tabular}

A recent meta-analysis of 11 case-control and 5 cohort studies also found no overall relationship with parity. ${ }^{58}$ Our result of no association with parity concurs with that meta-analysis.

Only a few epidemiologic studies have examined the association between duration of breastfeeding and lung cancer, and their results showed null effects. ${ }^{18,21,33}$ Those studies were all conducted in East Asia, and our null result is consistent with theirs.

Previous findings about the association between HRT and lung cancer are conflicting, with studies reporting a reduced risk, ${ }^{17,29,30}$ an increased risk ${ }^{27,28}$ and a null effect. ${ }^{15,16,19,23,25,31,32,49}$ A systemic review that analysed 6 case-control studies showed a protective association between HRT and lung cancer, ${ }^{59}$ but a recent metaanalysis of 14 cohort studies found no statistically significant association between HRT and lung cancer. ${ }^{60}$ Our largest-ever cohort study confirms the null association.

The epidemiologic literature is also inconsistent with regard to the role of oral contraceptives in lung cancer risk. Some case-control studies ${ }^{14,53,59}$ noted that women who had used an oral contraceptive had a decreased risk relative to women who had not used one. But most other studies reported a null association. ${ }^{18-20,22-26,51}$ A systemic review ${ }^{61}$ that analysed nine case-control and five cohort studies showed no statistically significant association between oral contraceptive use and lung cancer, which is consistent with our findings.

While not the focus of our study, our data show that smoking is a definite risk factor for the development of lung cancer, producing a clear dose-response relationship. In East Asia, smoking prevalence in females has been relatively low due to a social atmosphere that deters women from smoking. ${ }^{62}$ Indeed, in our study, only 3.1 and $1.1 \%$ women identified themselves as current or past smokers. The other $95.8 \%$ were never-smokers at cohort entry, and $92.0 \%$ of lung cancer patients were neversmokers. However, the female smoking rate is increasing, especially in younger populations, ${ }^{63}$ and there are many hidden smokers. ${ }^{62}$ Some studies suggest that women are more susceptible to tobacco carcinogenesis than men. ${ }^{64-66}$ In the absence of other potent risk factors for women, our study's results emphasise 







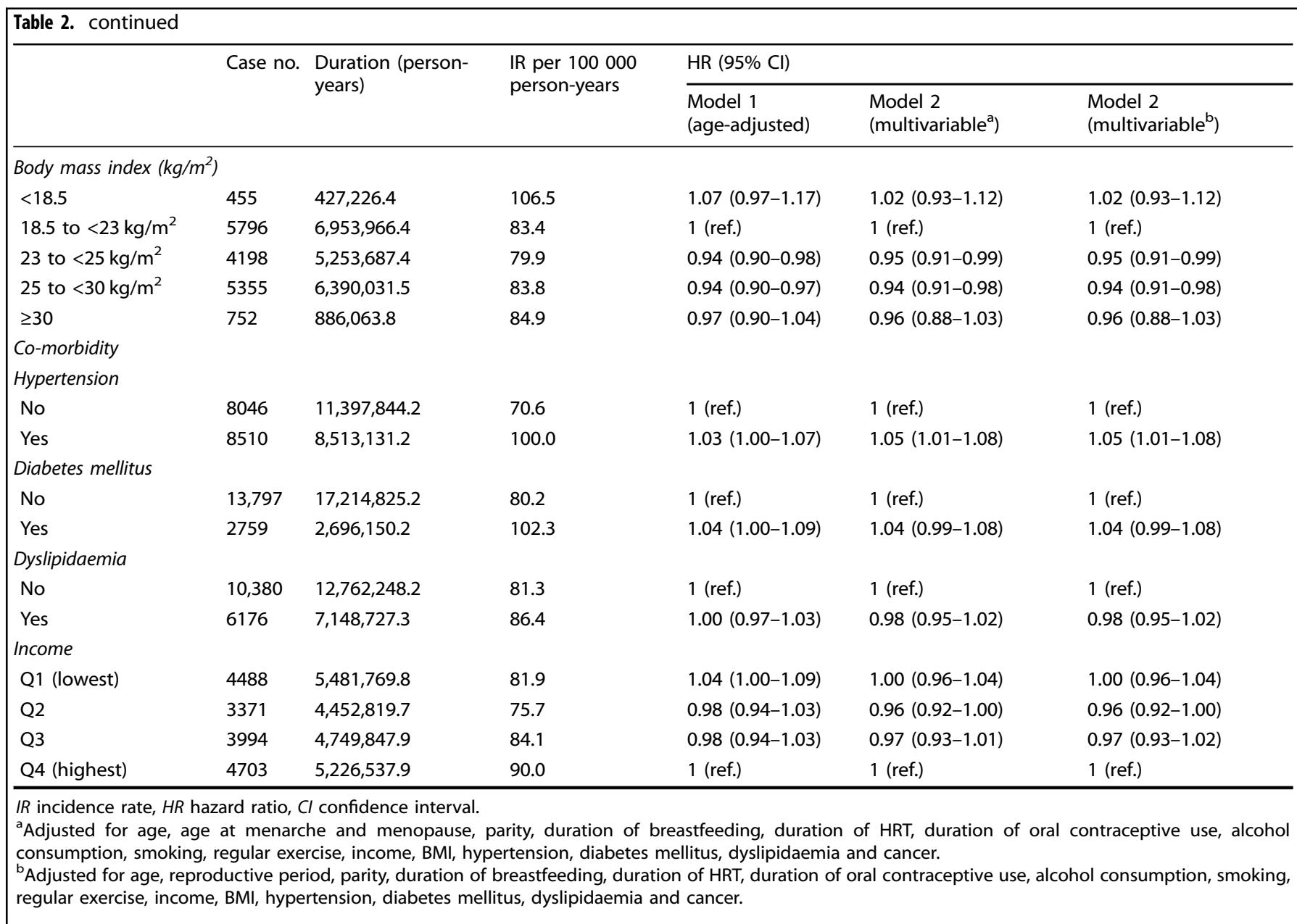

the importance of abstinence from smoking to prevent lung cancer in women.

In our study, having hypertension was slightly associated with an increase in lung cancer risk (aHR 1.05; 95\% Cl, 1.01-1.08) in women. Lindgren et al. reported that elevated blood pressure was associated with increased risk of lung cancer in smoking, hypertensive men, ${ }^{67}$ but most other cohort studies reported a null effect. ${ }^{68-72}$ The biological mechanism of such an association has rarely been investigated, but one recent study suggested that angiotensin-converting enzyme inhibitors are linked to a small increase in the risk of lung cancer and could be a potential confounder. ${ }^{73}$ Further studies are required to clarify this issue.

This study has several limitations. First, all the primary variables of interest were based on self-reported reproductive histories, and we therefore cannot exclude the possibility of bias caused by inaccurate recall. However, our data showed a null association, and it seems unlikely that recall bias could noticeably change that conclusion. Second, information on the components of HRT and oral contraceptives (e.g. oestrogen alone or oestrogen-progesterone) was unavailable. However, many studies, including the Women's Health Initiative trials, reported that neither the use of oestrogen plus progestin nor oestrogen alone was associated with lung cancer incidence, $28,74,75$ and the HRT formula is unlikely to affect our conclusion of no association. Third, information about other possible risk factors for lung cancer (second-hand smoke exposure, ${ }^{76-78}$ indoor pollutants ${ }^{79,80}$ and a family history of lung cancers ${ }^{14,81}$ ) was also unavailable. Fourth, our study participants were limited to health-screening participants and might be healthier and more engaged in having a healthy lifestyle than the general population.
Fifth, the follow-up period was relatively short at 4.4 years. Sixth, we could not include the pathological type of lung cancer because our data could not be linked to cancer registry data.

\section{CONCLUSIONS}

Overall, this study found no statistically significant association between reproductive factors or hormone use, and the risk of lung cancer in postmenopausal Korean women, among whom smoking prevalence is very low. Further studies are warranted to discover additional risk factors for lung cancer in the female population.

\section{ACKNOWLEDGEMENTS}

We thank the staff at the National Health Insurance Services for their provision of data and administrative support.

\section{AUTHOR CONTRIBUTIONS}

Study design: K.H.J., D.W.S., J.E.Y., S.-M.J. and J.H.C. Data assembly and analysis: K.-D.H. and D.K. Initial draft of the paper: K.H.J. All authors approved the paper.

\section{ADDITIONAL INFORMATION}

Ethics approval and consent to participate This study has been approved by the Institutional Review Board of Samsung Medical Center (IRB File No. SMC 2018-05020). The IRB has approved a waiver of the requirement to obtain informed consent from research participants. This study was performed in accordance with the Declaration of Helsinki. 
Consent to publish None.

Data availability The data that support the findings of this study are available from NHIS. Restrictions apply to the availability of these data, which were used under license for this study. Data are available at https://nhiss.nhis.or.kr with the permission of NIHS.

Competing interests The authors declare no competing interests.

\section{Funding information None.}

Supplementary information is available for this paper at https://doi.org/10.1038/ s41416-020-0789-7.

Note This work is published under the standard license to publish agreement. After 12 months the work will become freely available and the license terms will switch to a Creative Commons Attribution 4.0 International (CC BY 4.0).

Publisher's note Springer Nature remains neutral with regard to jurisdictional claims in published maps and institutional affiliations.

\section{REFERENCES}

1. Bray, F., Ferlay, J., Soerjomataram, I., Siegel, R. L., Torre, L. A. \& Jemal, A. Global cancer statistics 2018: GLOBOCAN estimates of incidence and mortality worldwide for 36 cancers in 185 countries. CA Cancer J. Clin. 68, 394-424 (2018).

2. Jung, K. W., Won, Y. J., Kong, H. J. \& Lee, E. S. Cancer statistics in Korea: Incidence, mortality, survival, and prevalence in 2016. Cancer Res. Treat. 51, 417-430 (2019).

3. Lewis, D. R., Check, D. P., Caporaso, N. E., Travis, W. D. \& Devesa, S. S. US lung cancer trends by histologic type. Cancer 120, 2883-2892 (2014).

4. Wakelee, H. A., Chang, E. T., Gomez, S. L., Keegan, T. H., Feskanich, D., Clarke, C. A. et al. Lung cancer incidence in never smokers. J. Clin. Oncol. 25, 472-478 (2007).

5. Cho, J., Choi, S. M., Lee, J., Lee, C. H., Lee, S. M., Kim, D. W. et al. Proportion and clinical features of never-smokers with non-small cell lung cancer. Chin. J. Cancer 36, 20 (2017).

6. Cheng, T. Y., Cramb, S. M., Baade, P. D., Youlden, D. R., Nwogu, C. \& Reid, M. E. The international epidemiology of lung cancer: latest trends, disparities, and tumor characteristics. J. Thorac. Oncol. 11, 1653-1671 (2016).

7. Zhou, F. \& Zhou, C. Lung cancer in never smokers-the East Asian experience. Transl. Lung Cancer Res. 7, 450-463 (2018).

8. Cheng, T. D., Darke, A. K., Redman, M. W., Zirpoli, G. R., Davis, W., Payne Ondracek, R. et al. Smoking, sex, and non-small cell lung cancer: steroid hormone receptors in tumor tissue (S0424). J. Natl. Cancer Inst. 110, 734-742 (2018).

9. Raso, M. G., Behrens, C., Herynk, M. H., Liu, S., Prudkin, L., Ozburn, N. C. et al. Immunohistochemical expression of estrogen and progesterone receptors identifies a subset of NSCLCs and correlates with EGFR mutation. Clin. Cancer Res. 15, 5359-5368 (2009).

10. Stabile, L. P., Davis, A. L., Gubish, C. T., Hopkins, T. M., Luketich, J. D., Christie, N. et al. Human non-small cell lung tumors and cells derived from normal lung express both estrogen receptor alpha and beta and show biological responses to estrogen. Cancer Res. 62, 2141-2150 (2002).

11. Stabile, L. P., Dacic, S., Land, S. R., Lenzner, D. E., Dhir, R., Acquafondata, M. et al. Combined analysis of estrogen receptor beta- 1 and progesterone receptor expression identifies lung cancer patients with poor outcome. Clin. Cancer Res. 17, 154-164 (2011)

12. Meert, A. P., Martin, B., Paesmans, M., Berghmans, T., Mascaux, C., Verdebout, J. M. et al. The role of HER-2/neu expression on the survival of patients with lung cancer: a systematic review of the literature. Br. J. Cancer 89, 959-965 (2003).

13. Taioli, E. \& Wynder, E. L. Re: endocrine factors and adenocarcinoma of the lung in women. J. Natl. Cancer Inst. 86, 869-870 (1994).

14. Wu, A. H., Yu, M. C., Thomas, D. C., Pike, M. C. \& Henderson, B. E. Personal and family history of lung disease as risk factors for adenocarcinoma of the lung. Cancer Res 48, 7279-7284 (1988).

15. Brinton, L. A., Gierach, G. L., Andaya, A., Park, Y., Schatzkin, A., Hollenbeck, A. R. et al. Reproductive and hormonal factors and lung cancer risk in the NIH-AARP Diet and Health Study cohort. Cancer Epidemiol. Biomark. Prev. 20, 900-911 (2011).

16. Baik, C. S., Strauss, G. M., Speizer, F. E. \& Feskanich, D. Reproductive factors, hormone use, and risk for lung cancer in postmenopausal women, the Nurses' Health Study. Cancer Epidemiol. Biomark. Prev. 19, 2525-2533 (2010).

17. Schwartz, A. G., Ray, R. M., Cote, M. L., Abrams, J., Sokol, R. J., Hendrix, S. L. et al. Hormone use, reproductive history, and risk of lung cancer: the women's health initiative studies. J. Thorac. Oncol. 10, 1004-1013 (2015).
18. Liu, Y., Inoue, M., Sobue, T. \& Tsugane, S. Reproductive factors, hormone use and the risk of lung cancer among middle-aged never-smoking Japanese women: a large-scale population-based cohort study. Int. J. Cancer 117, 662-666 (2005).

19. Seow, A., Koh, W. P., Wang, R., Lee, H. P. \& Yu, M. C. Reproductive variables, soy intake, and lung cancer risk among nonsmoking women in the Singapore Chinese Health Study. Cancer Epidemiol. Biomark. Prev. 18, 821-827 (2009).

20. Kabat, G. C., Miller, A. B. \& Rohan, T. E. Reproductive and hormonal factors and risk of lung cancer in women: a prospective cohort study. Int. J. Cancer 120, 2214-2220 (2007).

21. Tan, H. S., Tan, M. H., Chow, K. Y., Chay, W. Y. \& Lim, W. Y. Reproductive factors and lung cancer risk among women in the Singapore Breast Cancer Screening Project. Lung Cancer 90, 499-508 (2015).

22. Weiss, J. M., Lacey, J. V. Jr., Shu, X. O., Ji, B. T., Hou, L., Yang, G. et al. Menstrual and reproductive factors in association with lung cancer in female lifetime nonsmokers. Am. J. Epidemiol. 168, 1319-1325 (2008).

23. Meinhold, C. L., Berrington de Gonzalez, A., Bowman, E. D., Brenner, A. V., Jones, R. T., Lacey, J. V. Jr. et al. Reproductive and hormonal factors and the risk of nonsmall cell lung cancer. Int. J. Cancer 128, 1404-1413 (2011).

24. Gorlova, O. Y., Zhang, Y., Schabath, M. B., Lei, L., Zhang, Q., Amos, C. I. et al. Never smokers and lung cancer risk: a case-control study of epidemiological factors. Int. J. Cancer 118, 1798-1804 (2006).

25. Elliott, A. M. \& Hannaford, P. C. Use of exogenous hormones by women and lung cancer: evidence from the Royal College of General Practitioners' Oral Contraception Study. Contraception 73, 331-335 (2006).

26. Wu-Williams, A. H., Dai, X. D., Blot, W., Xu, Z. Y., Sun, X. W., Xiao, H. P. et al. Lung cancer among women in north-east China. Br. J. Cancer 62, 982-987 (1990).

27. Slatore, C. G., Chien, J. W., Au, D. H., Satia, J. A. \& White, E. Lung cancer and hormone replacement therapy: association in the vitamins and lifestyle study. $J$. Clin. Oncol. 28, 1540-1546 (2010).

28. Chlebowski, R. T., Schwartz, A. G., Wakelee, H., Anderson, G. L., Stefanick, M. L. Manson, J. E. et al. Oestrogen plus progestin and lung cancer in postmenopausal women (Women's Health Initiative trial): a post-hoc analysis of a randomised controlled trial. Lancet 374, 1243-1251 (2009).

29. Rodriguez, C., Spencer Feigelson, H., Deka, A., Patel, A. V., Jacobs, E. J., Thun, M. J. et al. Postmenopausal hormone therapy and lung cancer risk in the cancer prevention study II nutrition cohort. Cancer Epidemiol. Biomark. Prev. 17, 655-660 (2008).

30. Olsson, H., Bladstrom, A. \& Ingvar, C. Are smoking-associated cancers prevented or postponed in women using hormone replacement therapy? Obstet. Gynecol. 102, 565-570 (2003).

31. Clague, J., Reynolds, P., Sullivan-Halley, J., Ma, H., Lacey, J. V. Jr., Henderson, K. D. et al. Menopausal hormone therapy does not influence lung cancer risk: results from the California Teachers Study. Cancer Epidemiol. Biomark. Prev. 20, 560-564 (2011).

32. Smith, J. R., Barrett-Connor, E., Kritz-Silverstein, D., Wingard, D. L. \& Al-Delaimy, W. K. Hormone use and lung cancer incidence: the Rancho Bernardo cohort study. Menopause 16, 1044-1048 (2009).

33. Gallagher, L. G., Rosenblatt, K. A., Ray, R. M., Li, W., Gao, D. L., Applebaum, K. M. et al. Reproductive factors and risk of lung cancer in female textile workers in Shanghai, China. Cancer Causes Control 24, 1305-1314 (2013).

34. Pukkala, E., Tulenheimo-Silfvast, A. \& Leminen, A. Incidence of cancer among women using long versus monthly cycle hormonal replacement therapy, Finland 1994-1997. Cancer Causes Control 12, 111-115 (2001).

35. Schabath, M. B., Wu, X., Vassilopoulou-Sellin, R., Vaporciyan, A. A. \& Spitz, M. R. Hormone replacement therapy and lung cancer risk: a case-control analysis. Clin. Cancer Res. 10, 113-123 (2004).

36. Paez, J. G., Janne, P. A., Lee, J. C., Tracy, S., Greulich, H., Gabriel, S. et al. EGFR mutations in lung cancer: correlation with clinical response to gefitinib therapy. Science 304, 1497-1500 (2004).

37. Yano, T., Miura, N., Takenaka, T., Haro, A., Okazaki, H., Ohba, T. et al. Neversmoking nonsmall cell lung cancer as a separate entity: clinicopathologic features and survival. Cancer 113, 1012-1018 (2008).

38. Lee, H., Cho, J., Shin, D. W., Lee, S. P., Hwang, S. S., Oh, J. et al. Association of cardiovascular health screening with mortality, clinical outcomes, and health care cost: a nationwide cohort study. Prev. Med. 70, 19-25 (2015).

39. Yoo, K. Y. Cancer control activities in the Republic of Korea. Jpn. J. Clin. Oncol. 38, 327-333 (2008).

40. Lee, J., Lee, J. S., Park, S. H., Shin, S. A. \& Kim, K. Cohort profile: The National Health Insurance Service-National Sample Cohort (NHIS-NSC), South Korea. Int. J. Epidemiol. 46, e15 (2017).

41. Lee, Y. H., Han, K., Ko, S. H., Ko, K. S. \& Lee, K. U., Taskforce Team of Diabetes Fact Sheet of the Korean Diabetes Association. Data analytic process of a nationwide population-based study using National Health Information Database Established by National Health Insurance Service. Diabetes Metab. J. 40, 79-82 (2016). 
42. Lee, K. R., Hwang, I. C., Han, K. D., Jung, J. \& Seo, M. H. Waist circumference and risk of breast cancer in Korean women: a nationwide cohort study. Int. J. Cancer 142, 1554-1559 (2018).

43. Choi, Y. J., Lee, D. H., Han, K. D., Kim, H. S., Yoon, H., Shin, C. M. et al. The relationship between drinking alcohol and esophageal, gastric or colorectal cancer: a nationwide population-based cohort study of South Korea. PLOS ONE 12, e0185778 (2017)

44. Lee, J. H., Kim, H. J., Han, K. D., Kim, H. N., Park, Y. M., Lee, J. Y. et al. Cancer risk in 892089 patients with psoriasis in Korea: a nationwide population-based cohort study. J. Dermatol. 46, 95-102 (2019).

45. Shin, D. W., Cho, B. \& Guallar, E. Korean national health insurance database. JAMA Intern. Med. 176, 138 (2016).

46. Cheol Seong, S., Kim, Y. Y., Khang, Y. H., Heon Park, J., Kang, H. J., Lee, H. et al. Data resource profile: The National Health Information Database of the National Health Insurance Service in South Korea. Int. J. Epidemiol. 46, 799-800 (2017).

47. Brenner, A. V., Wang, Z., Kleinerman, R. A., Lei, S., Metayer, C., Wang, W. et al. Menstrual and reproductive factors and risk of lung cancer among Chinese women, Eastern Gansu Province, 1994-1998. J. Epidemiol. 13, 22-28 (2003).

48. Pesatori, A. C., Carugno, M., Consonni, D., Caporaso, N. E., Wacholder, S., Tucker, $M$. et al. Reproductive and hormonal factors and the risk of lung cancer: the EAGLE study. Int. J. Cancer 132, 2630-2639 (2013).

49. Lim, W. Y., Chen, Y., Chuah, K. L., Eng, P., Leong, S. S., Lim, E. et al. Female reproductive factors, gene polymorphisms in the estrogen metabolism pathway, and risk of lung cancer in Chinese women. Am. J. Epidemiol. 175, 492-503 (2012).

50. Koushik, A., Parent, M. E. \& Siemiatycki, J. Characteristics of menstruation and pregnancy and the risk of lung cancer in women. Int. J. Cancer 125, 2428-2433 (2009).

51. Schwartz, A. G., Wenzlaff, A. S., Prysak, G. M., Murphy, V., Cote, M. L., Brooks, S. C. et al. Reproductive factors, hormone use, estrogen receptor expression and risk of non small-cell lung cancer in women. J. Clin. Oncol. 25, 5785-5792 (2007)

52. Zatloukal, P., Kubik, A., Pauk, N., Tomasek, L. \& Petruzelka, L. Adenocarcinoma of the lung among women: risk associated with smoking, prior lung disease, diet and menstrual and pregnancy history. Lung Cancer 41, 283-293 (2003).

53. Kreuzer, M., Gerken, M., Heinrich, J., Kreienbrock, L. \& Wichmann, H. E. Hormonal factors and risk of lung cancer among women? Int. J. Epidemiol. 32, 263-271 (2003).

54. Seow, A., Poh, W. T., Teh, M., Eng, P., Wang, Y. T., Tan, W. C. et al. Diet, reproductive factors and lung cancer risk among Chinese women in Singapore: evidence for a protective effect of soy in nonsmokers. Int. J. Cancer 97, 365-371 (2002).

55. Paulus, J. K., Asomaning, K., Kraft, P., Johnson, B. E., Lin, X. \& Christiani, D. C. Parity and risk of lung cancer in women. Am. J. Epidemiol. 171, 557-563 (2010).

56. Matsuo, K., Ito, H., Yatabe, Y., Hiraki, A., Hirose, K., Wakai, K. et al. Risk factors differ for non-small-cell lung cancers with and without EGFR mutation: assessment of smoking and sex by a case-control study in Japanese. Cancer Sci. 98, 96-101 (2007).

57. Gao, Y. T., Blot, W. J., Zheng, W., Ershow, A. G., Hsu, C. W., Levin, L. I. et al. Lung cancer among Chinese women. Int. J. Cancer 40, 604-609 (1987).

58. Dahabreh, I. J., Trikalinos, T. A. \& Paulus, J. K. Parity and risk of lung cancer in women: systematic review and meta-analysis of epidemiological studies. Lung Cancer 76, 150-158 (2012).

59. Pesatori, A. C., Carugno, M., Consonni, D., Hung, R. J., Papadoupolos, A., Landi, M. T. et al. Hormone use and risk for lung cancer: a pooled analysis from the International Lung Cancer Consortium (ILCCO). Br. J. Cancer 109, 1954-1964 (2013)

60. Bae, J. M. \& Kim, E. H. Hormonal replacement therapy and the risk of lung cancer in women: an adaptive meta-analysis of cohort studies. J. Prev. Med. Public Health 48, 280-286 (2015).

61. Wu, W., Yin, Z. H., Guan, P., Ren, Y. W. \& Zhou, B. S. Association of oral contraceptives use and lung cancer risk among women: an updated meta-analysis based on cohort and case-control studies. Asian Pac. J. Cancer Prev. 15, 1205-1210 (2014)
62. Jung-Choi, K. H., Khang, Y. H. \& Cho, H. J. Hidden female smokers in Asia: a comparison of self-reported with cotinine-verified smoking prevalence rates in representative national data from an Asian population. Tob. Control 21, 536-542 (2012).

63. Hitchman, S. C. \& Fong, G. T. Gender empowerment and female-to-male smoking prevalence ratios. Bull. World Health Organ. 89, 195-202 (2011).

64. Ryberg, D., Hewer, A., Phillips, D. H. \& Haugen, A. Different susceptibility to smoking-induced DNA damage among male and female lung cancer patients. Cancer Res. 54, 5801-5803 (1994).

65. Thomas, L., Doyle, L. A. \& Edelman, M. J. Lung cancer in women: emerging differences in epidemiology, biology, and therapy. Chest 128, 370-381 (2005).

66. Dogan, S., Shen, R., Ang, D. C., Johnson, M. L., D'Angelo, S. P., Paik, P. K. et al. Molecular epidemiology of EGFR and KRAS mutations in 3,026 lung adenocarcinomas: higher susceptibility of women to smoking-related KRAS-mutant cancers. Clin. Cancer Res. 18, 6169-6177 (2012).

67. Lindgren, A., Pukkala, E., Nissinen, A. \& Tuomilehto, J. Blood pressure, smoking, and the incidence of lung cancer in hypertensive men in North Karelia, Finland. Am. J. Epidemiol. 158, 442-447 (2003).

68. Stocks, T., Van Hemelrijck, M., Manjer, J., Bjorge, T., Ulmer, H., Hallmans, G. et al. Blood pressure and risk of cancer incidence and mortality in the Metabolic Syndrome and Cancer Project. Hypertension 59, 802-810 (2012).

69. Inoue, M., Noda, M., Kurahashi, N., Iwasaki, M., Sasazuki, S., Iso, H. et al. Impact of metabolic factors on subsequent cancer risk: results from a large-scale population-based cohort study in Japan. Eur. J. Cancer Prev. 18, 240-247 (2009).

70. Rosengren, A., Himmelmann, A., Wilhelmsen, L., Branehog, I. \& Wedel, H. Hypertension and long-term cancer incidence and mortality among Swedish men. J. Hypertens. 16, 933-940 (1998).

71. Tulinius, H., Sigfusson, N., Sigvaldason, H., Bjarnadottir, K. \& Tryggvadottir, L. Risk factors for malignant diseases: a cohort study on a population of 22,946 Icelanders. Cancer Epidemiol. Biomark. Prev. 6, 863-873 (1997).

72. Grove, J. S., Nomura, A., Severson, R. K. \& Stemmermann, G. N. The association of blood pressure with cancer incidence in a prospective study. Am. J. Epidemiol. 134, 942-947 (1991)

73. Hicks, B. M., Filion, K. B., Yin, H., Sakr, L., Udell, J. A. \& Azoulay, L. Angiotensin converting enzyme inhibitors and risk of lung cancer: population based cohort study. BMJ 363, k4209 (2018).

74. Manson, J. E., Chlebowski, R. T., Stefanick, M. L., Aragaki, A. K., Rossouw, J. E., Prentice, R. L. et al. Menopausal hormone therapy and health outcomes during the intervention and extended poststopping phases of the Women's Health Initiative randomized trials. JAMA 310, 1353-1368 (2013).

75. Chlebowski, R. T., Anderson, G. L., Manson, J. E., Schwartz, A. G., Wakelee, H., Gass, $M$. et al. Lung cancer among postmenopausal women treated with estrogen alone in the women's health initiative randomized trial. J. Natl. Cancer Inst. 102, 1413-1421 (2010).

76. Wang, A., Kubo, J., Luo, J., Desai, M., Hedlin, H., Henderson, M. et al. Active and passive smoking in relation to lung cancer incidence in the Women's Health Initiative Observational Study prospective cohort. Ann. Oncol. 26, 221-230 (2015).

77. Kurahashi, N., Inoue, M., Liu, Y., Iwasaki, M., Sasazuki, S., Sobue, T. et al. Passive smoking and lung cancer in Japanese non-smoking women: a prospective study. Int. J. Cancer 122, 653-657 (2008).

78. Trichopoulos, D., Kalandidi, A., Sparros, L. \& MacMahon, B. Lung cancer and passive smoking. Int. J. Cancer 27, 1-4 (1981).

79. Xue, Y., Jiang, Y., Jin, S. \& Li, Y. Association between cooking oil fume exposure and lung cancer among Chinese nonsmoking women: a meta-analysis. Onco Targets Ther. 9, 2987-2992 (2016).

80. Janerich, D. T., Thompson, W. D., Varela, L. R., Greenwald, P., Chorost, S., Tucci, C. et al. Lung cancer and exposure to tobacco smoke in the household. N. Engl. J. Med. 323, 632-636 (1990).

81. Osann, K. E. Lung cancer in women: the importance of smoking, family history of cancer, and medical history of respiratory disease. Cancer Res. 51, 4893-4897 (1991). 